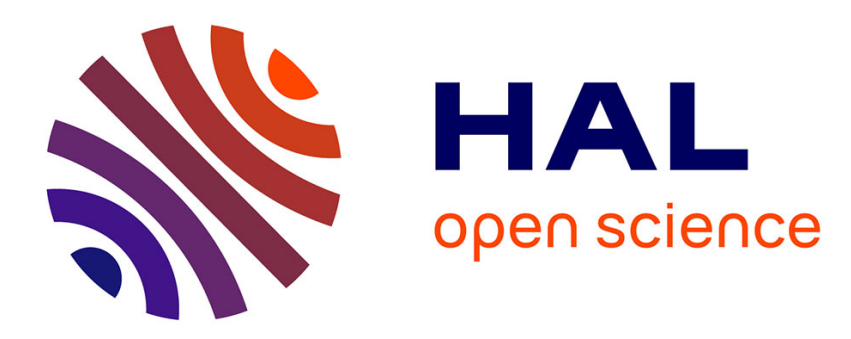

\title{
Carbon in Detonation Products. A "Three-Phase" Modelisation
}

\author{
M.-L. Turkel, F. Charlet
}

\section{To cite this version:}

M.-L. Turkel, F. Charlet. Carbon in Detonation Products. A "Three-Phase" Modelisation. Journal de Physique IV Proceedings, 1995, 05 (C4), pp.C4-407-C4-416. 10.1051/jp4:1995433 . jpa-00253738

\section{HAL Id: jpa-00253738 https://hal.science/jpa-00253738}

Submitted on 1 Jan 1995

HAL is a multi-disciplinary open access archive for the deposit and dissemination of scientific research documents, whether they are published or not. The documents may come from teaching and research institutions in France or abroad, or from public or private research centers.
L'archive ouverte pluridisciplinaire HAL, est destinée au dépôt et à la diffusion de documents scientifiques de niveau recherche, publiés ou non, émanant des établissements d'enseignement et de recherche français ou étrangers, des laboratoires publics ou privés. 


\title{
Carbon in Detonation Products. A "Three-Phase" Modelisation
}

\author{
M.-L. Turkel and F. Charlet* \\ Commissariat à l'Energie Atomique, Centre d'Etudes de Vaujours-Moronvilliers, BP. 7, 77181 Courtry, \\ France \\ * CISI, Centre de Saclay, BP. 28, 91192 Gif-sur-Yvette, France
}

\begin{abstract}
Condensed carbon is a common and rather abundant component in reactive mixtures formed in shock compressed energetic materials. However, there still remain some questions about its molecular forms in these mixtures. The choice of an accurate model to be used in high pressure, high temperature simulations is essential to ensure better prediction of energetic substances performances and constitutes a major difficulty. We describe the main theoretical features of a three-phase equation of state used in the thermochemical code CARTE to represent the graphite-diamond-liquid system. Sensitivity of different characteristics (detonation velocity, energy release) to carbon equation of state is investigated for a large range of energetic materials.
\end{abstract}

\section{INTRODUCTION}

Predictive calculations of explosives performances turns out to be essential to reduce the stages that lead to the conception and the selection of a new energetic molecule. It can be done with thermochemical codes like BKW [1], TIGER [2], ETARC[3], CHEQ [4] and some others, developed all over the world. Fluid phases present in the dense and hot mixture of detonation products can now be accurately described with equations of state based on statistical mechanical considerations or more empirical equations. It is not always the case for condensed phases of carbon appearing in oxygen-deficient environment that are rather poorly described in these codes. Some of the deviations observed between thermochemical calculations and experimental data could be explained by the poor description of these condensed phases or more simply by phase changes in carbon. An extensive effort was made over the last years to improve the description of carbon in detonation products.

A "three-phase" equation of state model was proposed by M. Van Thiel and F. H. Ree [5] to describe the graphite-diamond-liquid system and is used in CHEQ. This model is consistent with shock and thermal data and also with the latest results concerning the phase diagram of carbon. It was introduced in the new thermochemical code developed at the CEA (CARTE) and used to calculate the characteristics of the Chapman Jouguet state and the energy released during the isentropic expansion of detonation products. After a rapid presentation of the thermochemical code and a brief description of the "3 phase" model, we compare the results obtained with this new model to those obtained with a Cowan Fickett equation of state [6] for a large range of high explosives.

\section{THE THERMOCHEMICAL CODE CARTE}

Thermochemical calculations of energetic performances are based on physical hypotheses for the thermodynamic description of detonation products and numerical algorithms for the solving of the 
resulting equations. The different stages that arise in these predictive calculations are summarized in figure 1.

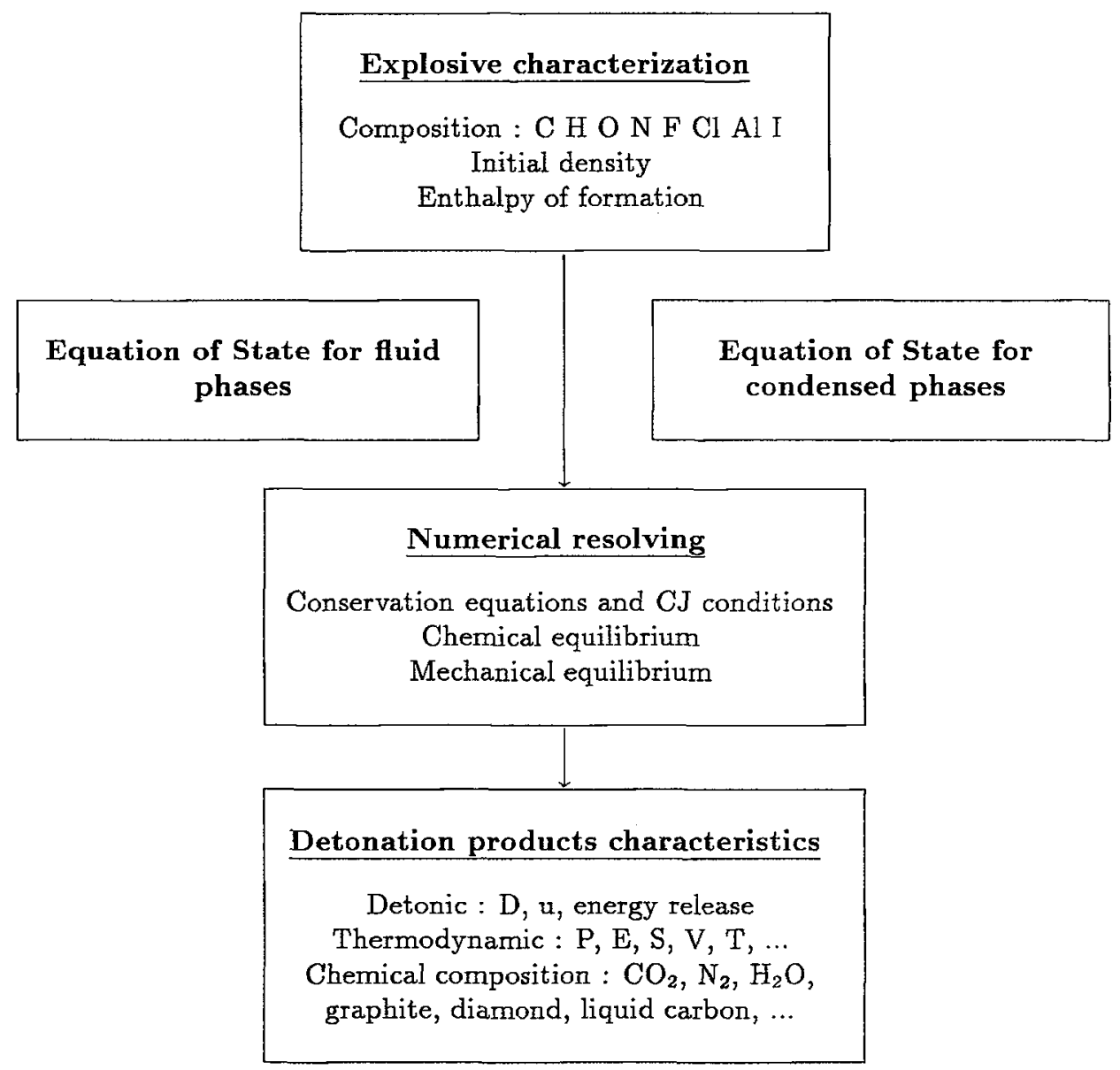

Figure 1: Organization of thermochemical calculations in the CARTE code.

The main properties of the CARTE code are:

-A large range of equations of state describing solid and fluid phases.

-Efficiency of numerical algorithms for the calculation of chemical equilibrium.

-Rapidity of calculations.

\section{Equations of State}

Several Equations of state are proposed to describe detonation products in a fluid phase:

* WCA : (4 different versions [3]) ; equations of state based on perturbation theory and used in the ETARC code.

* MCRSR : variational method developed by Ross [7] and used in CHEQ.

* THEOSTAR : accurate analytical equation developed by Byers-Brown [8], fitted on Monte Carlo data and WCA results (Ree version); used in the QUARTET code [9].

* BKW : empirical equation.

* JCZ : equation developed by Cowperthwaite [2] and used in TIGER. 
The equations of state for condensed phases are:

* Cowan-Fickett EOS [10] : empirical equation used in ETARC to describe graphite and diamond properties.

* Debye-Murnaghan EOS : used for graphite, diamond, solid aluminium and alumine.

* Three-phase EOS : used for the graphite-diamond-liquid system.

* Grover EOS [11] : used for liquid aluminium.

* Cowan EOS [12] : empirical equation used for liquid alumine.

\section{Numerical Performances}

Resolving of chemical equilibrium represents the main numerical difficulty in thermochemical calculations. Given $\mathrm{P}$ and $\mathrm{T}$, the equilibrium composition is determined by the minimum of the Gibbs free energy of the mixture. To illustrate the efficiency of numerical algorithms used in CARTE, we give, in table 1, a few comparisons of computation times for the determination of CJ isentropic expansions. The number of points calculated for each case is reported in brackets.

Table 1 : Calculation time comparisons.

\begin{tabular}{|c||c|c||c||c|c|}
\hline & ETARC & CARTE & CHEQ & CARTE \\
Explosive & CRAY YMP & Sparc 10 & Explosive & $\begin{array}{c}\text { Sparc 10 } \\
\text { Sparc 10 }\end{array}$ \\
\hline NM & $72 \mathrm{mn}(11 \mathrm{pts})$ & $39 \mathrm{~s}(50 \mathrm{pts})$ & HMX & $18348 \mathrm{~s}(50 \mathrm{pts})$ & $175 \mathrm{~s}(50 \mathrm{pts})$ \\
HMX compo. & $135 \mathrm{mn}(35 \mathrm{pts})$ & $48 \mathrm{~s}(50 \mathrm{pts})$ & & & \\
\hline
\end{tabular}

Equations of State used in the first calculations are WCA for the fluid phase and Cowan Fickett for the solid phase (graphite). For the second set, 2 fluid phases are considered and represented with the MCRSR equation of state ; condensed phases of carbon are described with the "Three-phase" model.

\section{THE "THREE-PHASE" EQUATION OF STATE}

The model proposed by M. Van Thiel anf F. H. Ree takes into account two solid phases and one liquid phase. This liquid phase is represented by the mixture of two different liquid structures.

\subsection{Solid phases description}

A Mie-Grüneisen formulation is used to represent solid phases properties. The pressure is defined by the sum of three contributions:

$$
P(V, T)=P_{\mathrm{oK}}(V)+P_{v, t h}(V, T)+P_{e, t h}(V, T)
$$

* The first term corresponding to the 0 kelvin isotherm is given by a modified Birch expansion.

$$
P_{0 K}(V)=\frac{3}{2} B_{0}\left[-B_{K} \eta^{3}+\left(1+2 B_{K}\right) \eta^{\frac{7}{3}}-\left(1+B_{K}\right) \eta^{\frac{5}{3}}\right] F(\eta)
$$

with

$$
F\left(\eta=V_{0 K} / V\right)=\left\{\begin{array}{ll}
\frac{1}{2}\left(\eta^{2}+\eta^{-2}\right) & \text { in expansion }(\eta<1) \\
1 & \text { in compression }(\eta>1)
\end{array}\right\}
$$

$B_{0}$ is the bulk modulus at $T=0$ and $P=0 . B_{K}=0.75\left(4-B_{0}^{\prime}\right)$ and $B_{0}^{\prime}$ is the pressure derivative of the bulk modulus. 
* The lattice thermal effects are approximated by the Einstein model:

$$
E_{v, t h}(V, T)=3 R \frac{\Theta_{E}}{e^{\frac{O_{E}}{T}}-1}
$$

In the Grüneisen approximation, the thermal pressure is related to the corresponding energy by:

$$
P_{v, t h}=\frac{\Gamma_{v}}{V} E_{v, t h}
$$

where the Grüneisen coefficient $\Gamma_{v}$ is related to the Einstein temperature $\Theta_{E}$ by:

$$
\Gamma_{v}=-\frac{\partial \ln \Theta_{E}}{\partial \ln V}
$$

An hyperbolic correction is used in the volume dependence of $\Gamma_{v}$ [13]:

$$
\frac{\Gamma_{v}(V)}{V}=\frac{\Gamma_{v_{0}}}{V_{0}}\left[1+\delta_{\gamma}(1+\tanh Z)\right] \quad \text { where } \quad Z=\frac{\left(V_{\gamma}-V\right)}{\delta V_{\gamma}}
$$

* The electronic thermal effects are represented by:

with

$$
P_{e, t h}(V, T)=\frac{\Gamma_{e}(V)}{2 V} g_{e} T^{2}
$$

$$
\Gamma_{e}(V)=\frac{d \ln g_{e}(V)}{d \ln V} \quad \text { and } \quad \frac{\Gamma_{e}(V)}{V}=C^{s t}
$$

Integration of equation 2 leads to the $0 \mathrm{~K}$ energy contribution. The integration constant $E_{0 K}\left(V_{0}\right)$ is given in table 2 . A correction to the entropy $\left(\delta S_{298}\right)$ is used to yield the proper value at 1 atmosphere and $298 K$ (it is a result of the imperfections of the Einstein approximation at low temperatures).

Graphite and diamond Hugoniots calculated with CARTE are represented on figures 2.a and 2.b. Graphite results are compared to the shock data of McQueen [14], Doran [15] and Coleburn [16]. Calculated diamond Hugoniot is compared to Pavlovski data [17]. The graphite-to-diamond transition is determined by the condition between the Gibbs free energies of the solids $G_{S_{g}}(P, T)=G_{S_{d}}(P, T)$ and compared to the experimental data of Berman [18] (figure 3).

Table 2 : Parameters of the "Three-phase" model for solid phases.

\begin{tabular}{|c|cc||c|cc|}
\hline Parameters & Graphite & Diamond & Parameters & Graphite & Diamond \\
& & & & & \\
\hline & & & & & \\
$V_{0}\left(\mathrm{~m}^{3} /\right.$ mole $)$ & $5.2738310^{-6}$ & $3.415110^{-6}$ & $B_{0}(G P a)$ & 51.10 & 439.7 \\
$E_{0} / R(K)$ & $(-0.0643)^{a}$ & $(243.7503)^{a}$ & $B_{0}^{\prime}$ & $7.1(5.0)^{b}$ & 3.65 \\
$\Gamma_{v_{0}}$ & 0.35 & 1.15 & $\delta S_{298} / R$ & 0.464 & 0.1331 \\
$\Gamma_{e_{0}}$ & 0.24 & 1.10 & $\delta_{\gamma}$ & 3.0 & 0.0 \\
$\Theta_{E_{0}}(K)$ & 1280 & 1411 & $\delta V_{\gamma}\left(\mathrm{cm}^{3} / \mathrm{g}\right)$ & 0.065 & 1.0 \\
$g_{e_{0}} / R(K)$ & $1.15610^{-6}$ & 0.0 & $V_{\gamma}\left(\mathrm{cm}^{3} / \mathrm{g}\right)$ & 0.22 & 0.0 \\
& & & & & \\
\hline
\end{tabular}


() The reference state (zero enthalpy for graphite) is 0 Kelvin.

() $)^{b}$ This value is used for expanded states.
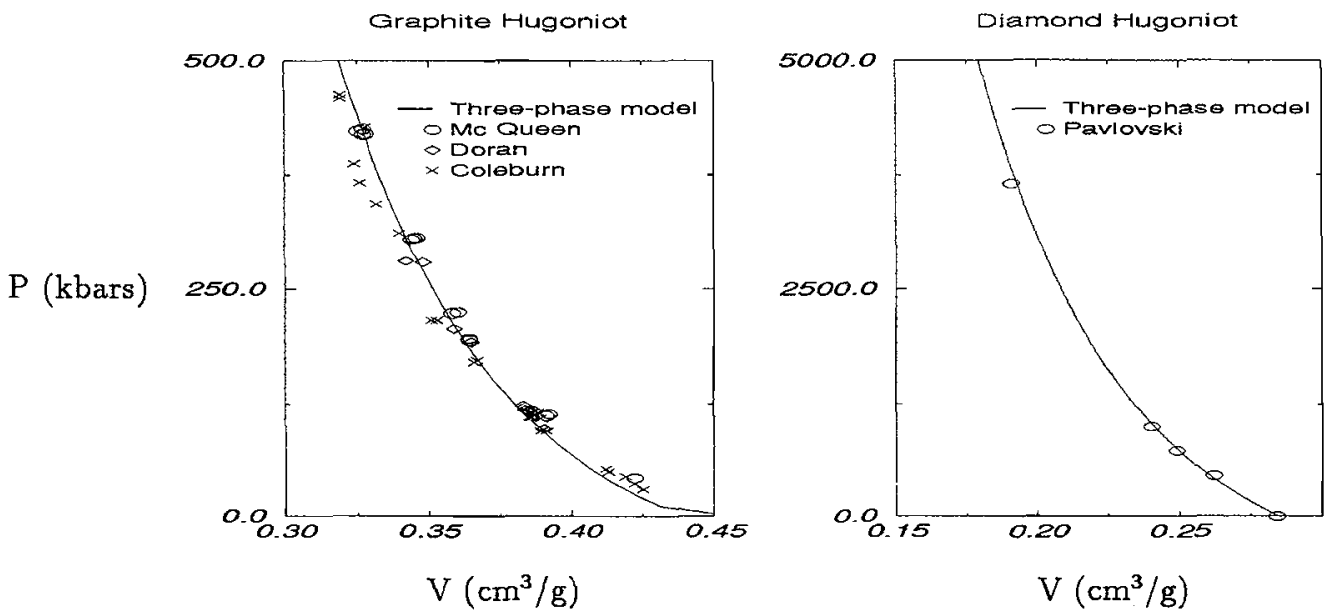

Figure 2: Comparison between calculated Hugoniot and shock data.

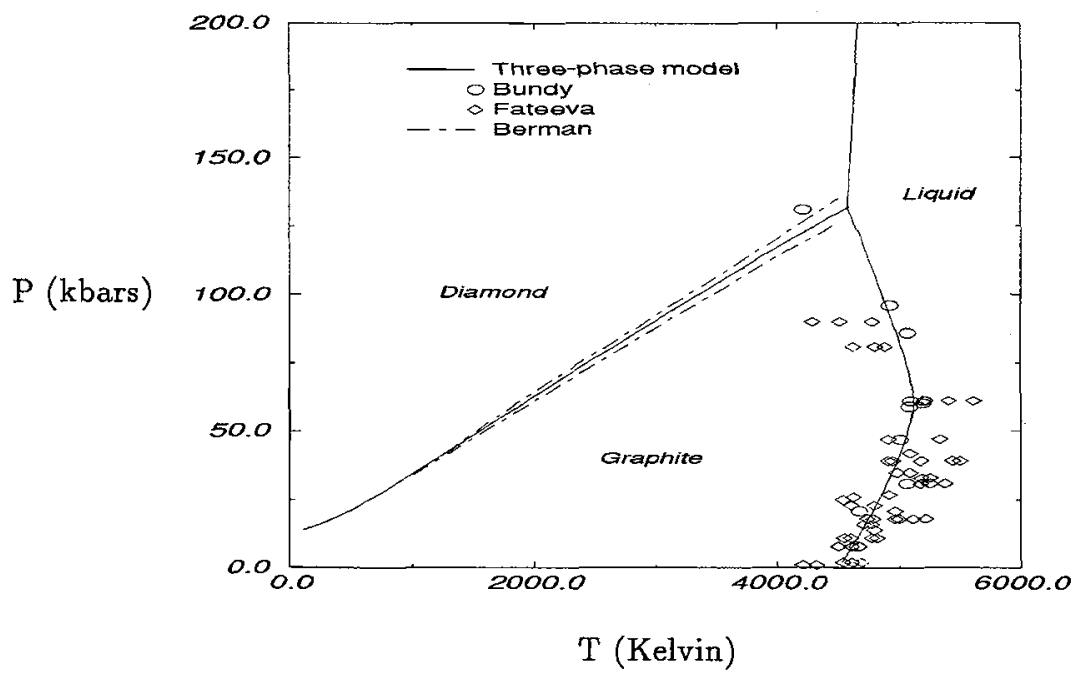

Figure 3: Comparison between the carbon phase-diagram calculated with the "Three-phase" equation of state model and experimental data. 


\subsection{Liquid phase description}

The liquid phase consists of a mixture of two liquid structures, a graphitic one and a diamond-like one. The thermodynamic properties of these liquid states are calculated from the corresponding solid states properties by the scaling model of Grover [11]. The liquid heat capacity is deduced from the solid one by:

$$
C_{V_{L}}=C_{V_{S}}^{*}-\frac{3}{2} R \frac{\alpha \tau}{1+\alpha \tau}
$$

where:

$$
C_{V_{S}}^{*}=C_{V_{S, v}}+g_{e_{L}} T
$$

and

$$
\tau=\frac{T}{T_{m}}
$$

$T_{m}$, the melting temperature is represented by a Lindemann law. The formulation used for the diamond case is:

$$
T_{m}=\text { const. } M \Theta_{E}^{2} V_{m}^{\frac{2}{3}}
$$

where $M$ is the molar weight and $V_{m}$ the molar volume in solid state. For the anisotropic case of graphite, an anharmonic correction is needed $[19,20]$ :

$$
T_{m}=\text { const. } M \Theta_{E}^{2} V_{m}^{\frac{2}{3}}\left(\frac{a}{c}\left(V_{m}\right)\right)^{\frac{2}{3}}\left[\left(1-f\left(V_{m}\right)\right)+f\left(V_{m}\right)\left(\frac{c}{a}\left(V_{m}\right)\right)\right]^{2}
$$

with

$$
\frac{c}{a}\left(V_{m}\right)=0.2488+0.2109 V_{m} \quad\left(V_{m} \text { is given in } \mathrm{cm}^{3} / \mathrm{mole}\right)
$$

and

$$
f\left(V_{m}\right)=0.35 / V_{m}^{\frac{1}{2}} \quad\left(V_{m} \text { is given in } \mathrm{cm}^{3} / \text { mole }\right)
$$

Integration of equation 9 leads to the following entropy:

$$
S_{L}(V, T)=S_{S}(V, T)+\Delta S_{m}+\Delta S_{e}(V, T)-\frac{3}{2} R \ln \left(\frac{1+\alpha \tau}{1+\alpha}\right)
$$

where $\Delta S_{e}$ is a correction due to the modification of electronic properties between solid and liquid states (through a modification of the $g_{e}$ parameter). $\Delta S_{m}$ is a melting entropy.

The Gibbs free energies of the two liquid states are then calculated and the free energy of the mixture is given by the mixing law:

$$
G_{L}(P, T, x)=x G_{L_{g}}(P, T)+(1-x) G_{L_{d}}(P, T)+R T[x \ln x+(1-x) \ln (1-x)]+A_{s}(T, P, x)
$$

where

$$
A_{s}(T, P, x)=R T\left[\frac{A_{S, 0}}{1+\left(\frac{P}{P_{0}^{\prime}}\right)^{\frac{3}{2}}}\right] x(1-x)
$$


The liquid phase is completely characterised by the molar fraction $\mathrm{x}$ of graphite-like liquid in the mixture. This can be done, for a given $(P, T)$ state, by minimizing the Gibbs free energy of the mixture with respect to $x$.

The parameters used to calculate liquid states properties, differing slightly from those proposed by Van Thiel and Ree [21], are given in table 3.

Table 3 : Parameters of the "Three-phase" model for liquid states.

\begin{tabular}{|c|ccc|}
\hline Parameters & $\begin{array}{c}\text { graphite-like } \\
\text { liquid }\end{array}$ & $\begin{array}{c}\text { diamond-like } \\
\text { liquid }\end{array}$ & Mixture \\
\hline$\Gamma_{e_{0}, L}$ & 0.24 & 1.10 & \\
$g_{e_{0}, L} / R(K)$ & $1.15610^{-6}$ & $6.03810^{-5}$ & \\
$T_{m, 0}(K)$ & 6000 & 5900 & \\
$\Delta S_{m} / R$ & 2.557 & 1.007 & \\
$A_{S, 0}$ & & & 2.2 \\
$P_{0}^{\prime}(G P a)$ & & & 22 \\
\hline
\end{tabular}

The melting line of graphite, determined by the condition $G_{L}(P, T)=G_{S_{g}}(P, T)$, is represented on figure 3 and compared to experimental data of Bundy [22] and Fateeva [23]. The data of Fateeva corresponding to a graphite-liquid-gas triple point temperature of $4000 \mathrm{~K}$ have been corrected by adding the same $\Delta T$ to all values, according to the new estimation of this triple point temperatue (4500K). The curvature of the calculated graphite melting line seems to be smaller than the experimental ones. A better agreement could be obtained by increasing the parameter $A_{S, 0}$, but the result would be a liquid-liquid phase transition in carbon which should need an experimental confirmation.

In the same way, the diamond melting line can be determined by $G_{L}(P, T)=G_{S_{d}}(P, T)$. Results are consistent with the last experimental data indicating a positive diamond-melting-line slope.

\section{THERMOCHEMICAL CALCULATIONS}

CJ characteristics and energetic performances were calculated for a large range of explosives. This means various chemical compositions and a large range of density, enthalpy of formation and oxygenbalance (negative in all cases). In these calculations, the fluid phase properties were described with a WCA equation of state.

\section{$4.1 \mathrm{CJ}$ properties}

The Chapman Jouguet characteristics calculated with the Cowan Fickett equation of state (CF) and with the "Three-phase" model (3P) for carbon are given in table 4.

In CJ conditions, for most explosives, both equations of state predict diamond as the stable phase. In this case, the new equation of state seems to give better predictions of detonation velocities. For the last 3 explosives designated by M2, M3 and M5, the "Three-phase" equation of state predicts liquid carbon $(\mathrm{L})$. Calculated $\mathrm{CJ}$ characteristics are then very different. Unfortunately, there are no experimental data concerning these new molecules, not synthetised at this time and for which the uncertainty on the determination of density and enthalpy of formation is relatively important.

The CJ temperatures and pressures of these explosives have been reported on the phase diagram of carbon calculated with the "Three-phase" model and given in figure 4 . 
Table 4: Comparison of $\mathrm{CJ}$ characteristics and energetic performances.

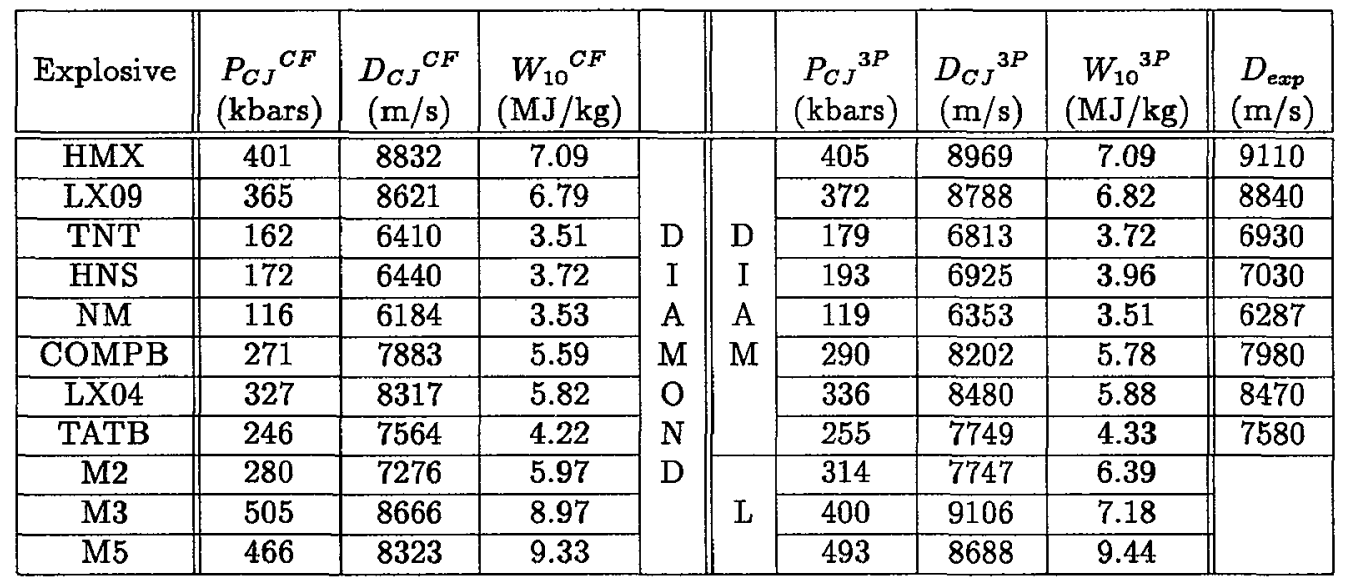

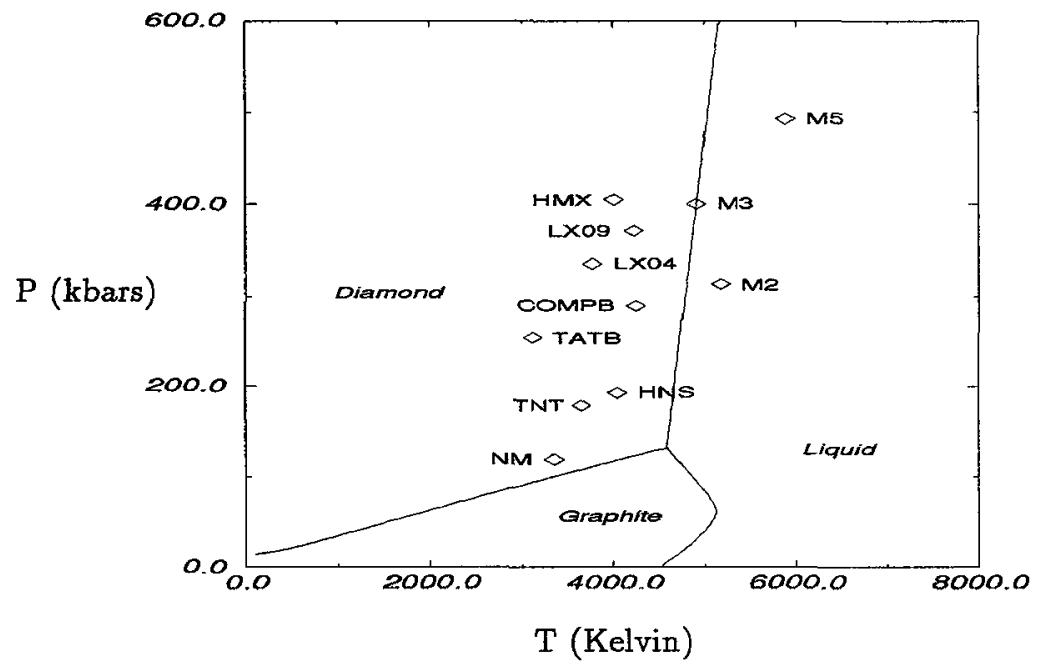

Figure 4: Chapman-Jouguet characteristics and carbon phase-diagram.

\subsection{Energetic considerations}

The energetic contents of these explosives can be represented by the work provided by detonation products during their isentropic expansion. The $(P, V)$ curves calculated with the CARTE code are then integrated from the CJ point to $10 \mathrm{kbars}\left(\int_{10 \text { hbars }}^{P_{C J}} P d V\right)$. Results are listed in table 4 . The energy released greatly differs when carbon appears in liquid phase. An illustration of these calculations is given in figure 5 for the particular case of TNT. The phase transition between graphite and diamond appens for different pressures, depending on the carbon equation of state used.

Cylinder-expansion experiments are the usual test to evaluate energetic performances of new molecules and compositions. The $(P, V)$ curves calculated with CARTE can be transformed with a simple model, 
to give expansion velocity as a function of cylinder expansion. Results obtained for TNT (copper cylinder : $r_{i}=12.7 \mathrm{~mm}, r_{e}=15.306 \mathrm{~mm}$ ) are compared on figure 6 to LLNL experimental data.

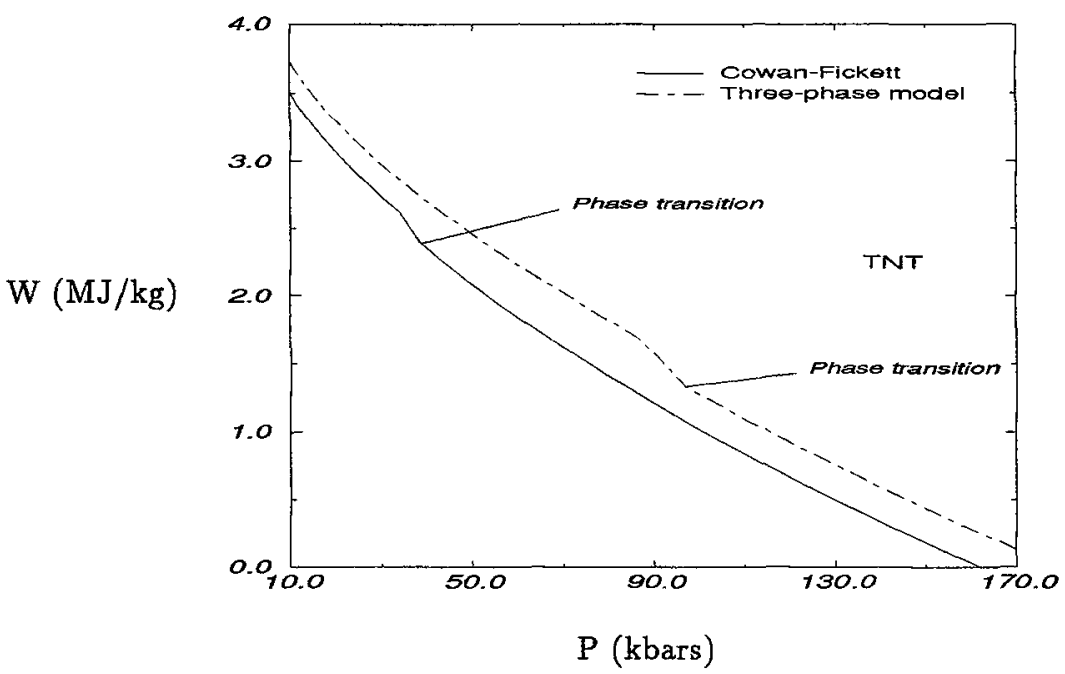

Figure 5: Work of TNT detonation products during their isentropic expansion from the CJ point to 10 kbars.

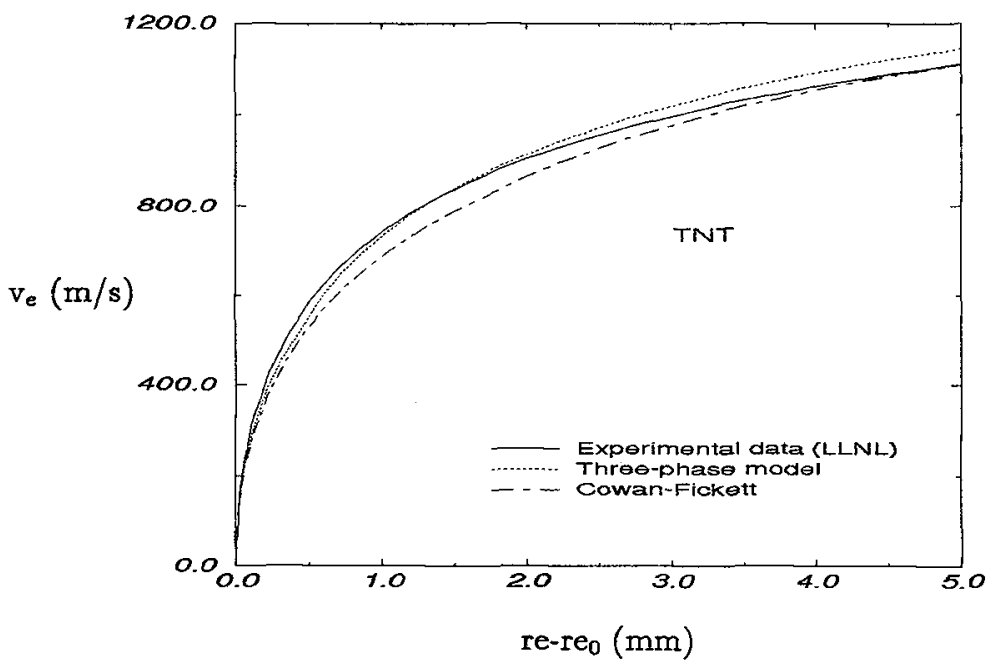

Figure 6: TNT expansion velocity function of external radius variation. 


\section{CONCLUSION}

Some theoretical features of a Three-phase Equation of State model for carbon have been described. This model is rapid enough to be used in chemical equilibrium theory and sufficiently accurate to fit the latest results on carbon phase diagram. The influence of the carbon equation of state on detonation characteristics calculated with the thermochemical code CARTE is obvious. Introduction of a liquid phase in these calculations can considerably modify predicted performances.

\section{References}

[1] Mader C. L., "Numerical modeling of detonation", (University of California, Los Angeles, 1979).

[2] Cowperthwaite M., Zwisler W. H., VI symposium on Detonation, White Oak 24-27 August 1976, (Office of Naval Research, Arlington, Virginia, 1976) pp. 162-170.

[3] Chirat R., Pittion-Rossillon G., J. Chem. Phys. 74(8) (1981) 4634.

[4] Ree F. H., J. Chem. Phys. 81 (1984) 1251-1263.

[5] Van Thiel M., Ree F. H., J. Appl. Phys. 62 (1987) 1761.

[6] Cowan R. D., Fickett W. J., J. Chem. Phys. 24(5) (1956) 932.

[7] Ross M., J. Chem. Phys. 71 (1979) 1567.

[8] Byers Brown W., J. Chem. Phys. 87 (1987) 566-577.

[9] Heuzé O., "QUARTET ; Système de Calcul et de Simulation Thermochimique", (Softworld, Paris, 1991)

[10] Baute J., Chirat R., Eighth International Symposium on Detonation, Albuquerque 15-19 July 1985, (Naval Surface Weapons Center, Maryland, USA, 1985) pp. 521-530.

[11] Grover R., Proc. of the $7^{\text {th }}$ Symp. of Thermophysical Properties, (1977) p 67.

[12] Jones H. D., Gray M. V., Comb. and Flame 64 (1986) 185.

[13] Van Thiel M., Ree F. H., Int. J. of Thermophysics 10(1) (1989) 227.

[14] Mc Queen R. G., Marsh S. P., Symposium on High Dynamic Pressures, (Paris, France, 1967).

[15] Doran D. G., J. Appl. Phys. 34(4) (1964) 844.

[16] Coleburn N. L., J. Chem. Phys. 40(1) (1964) 71.

[17] Pavlovski M. N., Soviet Physics - Solid State 13(3) (1971) 741.

[18] Berman R., Simon F., Z. Electrochem. 59 (1955) 333.

[19] Van Thiel M., Ree F. H., Phys. Review B 48(6) (1993) 3591.

[20] Van Thiel M., Ree F. H., High Pressure Research 10 (1992) 607.

[21] Van Thiel M., Ree F. H., High Temp. High Press. 24 (1992) 195.

[22] Bundy F. P., Proc. of the XI AIRAPT Int. Conf. (Kiev, USSR, july 1987).

[23] Fateeva N. S., Vereshchagin L. F., ZhETF Pis. Red. 13(3) (1971) 157. 